\title{
Genetic testing for ventricular septal defect
}

\author{
Yeltay Rakhmanov ${ }^{1}$, Paolo Enrico Maltese ${ }^{1 \star}$, Francesca Fanelli², Tommaso Beccari ${ }^{3}$, Munis Dundar ${ }^{4}$, \\ and Matteo Bertelli1,2
}

\begin{abstract}
Ventricular septal defects (VSDs) are the commonest heart malformations and may affect the membranous or the muscular septum. Clinical presentation depends on the amount of interventricular flow, which is determined by the size of the defect and the relative resistances of the pulmonary and systemic vascular beds. The prevalence of VSD is estimated at about $5 \%$ among infants. Many small malformations present at birth may later undergo spontaneous closure. VSD may have autosomal dominant or autosomal recessive inheritance and may exist as isolated forms or as part of a syndrome. This Utility Gene Test was developed on the basis of an analysis of the literature and existing diagnostic protocols. It is useful for confirming diagnosis, as well as for differential diagnosis, couple risk assessment and access to clinical trials.
\end{abstract}

\section{Keywords: Ventricular Septal Defect, EBTNA UTILITY GENE TEST}

${ }^{1}$ MAGI's Lab, Rovereto, Italy

${ }^{2}$ MAGI Euregio, Bolzano, Italy

${ }^{3}$ Department of Pharmaceutical Sciences, University of Perugia, Perugia, Italy

${ }^{4}$ Department of Medical Genetics, Erciyes University Medical School, Kayseri, Turkey

*Corresponding author: P. E. Maltese E-mail: paolo.maltese@assomagi.org DOI: 10.2478/ebtj-2018-0037
C 2018 Authors. This work was licensed under the Creative Commons AttributionNonCommercial-NoDerivs 3.0 License.

\section{General information about the disease}

Ventricular septal defects (VSDs) are the commonest congenital cardiac malformations. They may exist in isolated form or in combination with other anomalies, such as part of tetralogy of Fallot, or with double outlet right ventricle or common arterial trunk (1).

According to Soto et al. these malformations can be divided into membranous and muscular septal defects. The membranous septum is smaller than the muscular septum and is located at the base of the heart, below the right and noncoronary cusps of the aortic valve, between the inlet and outlet components of the muscular septum. The muscular septum is a nonplanar structure consisting of inlet, trabecular and infundibular components $(2,3)$.

The pathogenesis of VSD primarily depends on the amount and direction of interventricular shunting and volume loading of the heart chambers. Prolapse of the aortic valve and obstruction of the pulmonary or systemic outflow tract are considered to be secondary effects (4).

The manifestation of clinical symptoms is directly linked to the entity of interventricular flow, which is determined by the size of the defect and the relative resistances of the pulmonary and systemic vascular beds (4).

The prevalence of VSD is estimated at about 5\% among infants. Many small malformations present at birth may later undergo spontaneous closure. Patients with medium and larger VSDs can undergo to severe complications such as arrhythmias, pulmonary arterial hypertension, ventricular dysfunction, congestive heart failure or develop Eisenmenger syndrome $(3,5)$.

$\mathrm{Du}$ et al. reported a high prevalence of VSD (56.6/1000 live births) among preterm neonates (6). This defect is the commonest congenital malformation of the heart at one week of age and in the first three decades of life: $32.1 \%$ of all patients with congenital heart disease have ventricular septal defects (7). 
Diagnosis is based on clinical assessment to identify symptoms, echocardiogram, electrocardiogram, chest radiogram, integration of septal, colour Doppler and twodimensional echocardiography, spin-echo MR imaging, CT, diagnostic catheterization and genetic testing (3).

Differential diagnosis should consider VSD caused by Down syndrome and other chromosomal disorders $(8,9)$.

\section{Autosomal dominant syndromic VSD}

- Apert and Crouzon syndromes (OMIM diseases 101200 and 123500, respectively) - FGFR2 (OMIM gene 176943) (10);

- Atrioventricular septal defect, partial, with heterotaxy syndrome (AVSD2, OMIM disease 606217) - CRELD1 (OMIM gene 607170);

- Cardiofaciocutaneous syndrome 1 (CFC1, OMIM disease 115150) - BRAF (OMIM gene 164757);

- Cornelia de Lange syndrome 3 (CDLS3, OMIM disease 610759) - SMC3 (OMIM gene 606062);

- Holt-Oram syndrome (HOS, OMIM disease 142900) TBX5 (OMIM gene 601620);

- Kabuki syndrome 1 (KABUK1, OMIM disease 147920) MLL2 (OMIM gene 602113);

- Mowat-Wilson syndrome (MOWS, OMIM disease 235730) - ZEB2 (OMIM gene 605802);

- Myhre syndrome (MYHRS, OMIM disease 139210) SMAD4 (OMIM gene 600993);

- Noonan Syndrome 1 (NS1, OMIM disease 163950) PTPN11 (OMIM gene 176876).

- Dilated cardiomyopathy-1S and (CMD1S, OMIM disease 613426) and Ebstein anomaly (OMIM disease 224700) MYH7 (OMIM gene 160760) (11, 12);

- Aortic valve disease 1 (AVD1, OMIM disease 109730) NOTCH1 (OMIM gene 190198) (13);

- Visceral heterotaxy 5 (HTX5, OMIM disease 270100) NODAL (OMIM gene 601265) (14).

\section{Autosomal recessive syndromic VSD}

- Ellis-van Creveld syndrome (EVC, OMIM disease 225500) - EVC (OMIM gene 604831), EVC2 (OMIM gene: 607261);

- Right atrial isomerism (RAI, OMIM disease 208530) - GDF1 (OMIM gene 602880) (15).

\section{Autosomal dominant non-syndromic VSD}

- Ventricular septal defect 1 (VSD1, OMIM disease 614429) GATA4 (OMIM gene 600576);

- Ventricular septal defect 2 (VSD2, OMIM disease 614431) CITED2 (OMIM gene 602937);

- Ventricular septal defect 3 (VSD3, OMIM disease 614432) NKX2-5 (OMIM gene 600584);

- TWIST1 (OMIM gene 601622) (16);

- HAS2 (OMIM gene 601636) (17);

- NKX2-6 (OMIM gene 611770) (18);

- GATA6 (OMIM gene 601656) (19);

- HOMEZ (OMIM gene 608119) (20);

- HAND1 (OMIM gene 602406) (21);
- FOXH1 (OMIM gene 603621) (22);

- TBX2 (OMIM gene 600747) (23);

- HAND2 (OMIM gene 602407) (24).

\section{Other likely genes}

TNNI3 (OMIM gene 191044) (25), SALL4 (OMIM gene 607343) (26), TDGF1 (OMIM gene 187395) (27), GDF3 (OMIM gene 606522) (28), HIRA (OMIM gene 600237) (29), GNB1L (OMIM gene 610778) (29), and TUBA8 (OMIM gene 605742) (29).

The vast majority of these genes are key components of the Nodal signaling pathway that is important for specification and patterning of vertebrate embryos (30) and in mammalian cardiac development (31).

Pathogenic variants may include missense, nonsense, splicing, small insertions/deletions, small indels, gross deletions/insertions and regulatory substitutions.

\section{Aims of the test}

- To determine the gene defect responsible for the disease;

- To confirm clinical diagnosis;

- To assess the recurrence risk and perform genetic counselling for at-risk/affected individuals.

\section{Test characteristics}

\section{Specialist centers/ Published Guidelines}

Guidelines for clinical use of the test are described in Genetics Home Reference (ghr.nlm.nih.gov) and Gene Reviews (32).

\section{Test strategy}

Clinically distinguishable syndromes can be analyzed by sequencing only those genes known to be associated with that specific disease using Sanger or Next Generation Sequencing (NGS); if the results are negative, or more generally if clinical signs are ambiguous for diagnosis, a multi-gene NGS panel is used to detect nucleotide variations in coding exons and flanking introns of the above genes.

Potentially causative variants and regions with low coverage are Sanger-sequenced. Sanger sequencing is also used for family segregation studies.

Multiplex Ligation Probe Amplification (MLPA) is used to detect duplications and deletions in CRELD1, EVC, EVC2, GATA4, MLL2, NKX2-5 and TBX5.

To perform molecular diagnosis, a single sample of biological material is normally sufficient. This may be $1 \mathrm{ml}$ peripheral blood in a sterile tube with $0.5 \mathrm{ml} \mathrm{K}$ EDTA or $1 \mathrm{ml}$ saliva in a sterile tube with $0.5 \mathrm{ml}$ ethanol $95 \%$. Sampling rarely has to be repeated.

Gene-disease associations and the interpretation of genetic variants are rapidly developing fields. It is therefore possible that the genes mentioned in this note may change as new scientific data is acquired. It is also possible that genetic variants today defined as of "unknown or uncertain significance" may acquire clinical importance. 


\section{Genetic test results}

\section{Positive}

Identification of pathogenic variants in the aforementioned genes confirms the clinical diagnosis and is an indication for family studies.

A pathogenic variant is known to be causative for a given genetic disorder based on previous reports or predicted to be causative based on the loss of protein function or expected significant damage to protein or protein/protein interactions. In this way it is possible to obtain a molecular diagnosis in new/other subjects, establish the risk of recurrence in family members and plan preventive and/or therapeutic measures.

\section{Inconclusive}

Detection of a variant of unknown or uncertain significance (VUS): a new variation without any evident pathogenic significance or a known variation with insufficient evidence (or with conflicting evidence) to indicate it is likely benign or likely pathogenic for a given genetic disorder. In these cases, it is advisable to extend testing to the patient's relatives to assess variant segregation and clarify its contribution. In some cases, it could be necessary to perform further examinations/tests or to do a clinical reassessment of pathological signs.

\section{Negative}

The absence of variations in the genomic regions investigated does not exclude a clinical diagnosis but suggests the possibility of:

- alterations that cannot be identified by sequencing, such as large rearrangements that cause loss (deletion) or gain (duplication) of extended gene fragments;

- sequence variations in gene regions not investigated by this test, such as regulatory regions (5' and 3' UTR) and deep intronic regions;

- variations in other genes not investigated by the present test.

\section{Unexpected}

Unexpected results may come out from the test, for example information regarding consanguinity; absence of family correlation or the possibility of developing genetically based diseases.

\section{Risk for progeny}

If the identified pathogenic variant has autosomal dominant transmission, the probability that an affected carrier transmit the disease variant to his/her children is $50 \%$ in any pregnan$c y$, irrespective of the sex of the child conceived.

In autosomal recessive mutations, both parents are usually healthy carriers. In this case, the probability of transmitting the disorder to the offspring is $25 \%$ in any pregnancy of the couple, irrespective of the sex of the child. An affected individual generates healthy carrier sons and daughters in all cases, except in pregnancies with a healthy carrier partner In these cases, the risk of an affected son or daughter is $50 \%$.

\section{Limits of the test}

The test is limited by current scientific knowledge regarding the gene and disease.

Analytical sensitivity (proportion of positive tests when the genotype is truly present) and specificity (proportion of negative tests when the genotype is not present)

NGS Analytical sensitivity $>99.99 \%$, with a minimum coverage of 10X; Analytical specificity $99.99 \%$.

SANGER Analytical sensitivity $>99.99 \%$; Analytical specificity 99.99\%.

MLPA Analytical sensitivity $>99.99 \%$; Analytical specificity 99.99\%.

Clinical sensitivity (proportion of positive tests if the disease is present) and clinical specificity (proportion of negative tests if the disease is not present)

Clinical sensitivity: variations in the aforementioned genes are linked to VSD, but may be individual variations (identified in one or a few families) and total epidemiological data is therefore not available. Clinical sensitivity will be estimated based on internal cases.

Clinical specificity: is estimated at approximately $99 \%$ (33).

\section{Prescription appropriateness}

The genetic test is appropriate when:

a) the patient meets the diagnostic criteria for VSD;

b) the sensitivity of the test is greater than or equal to that of tests described in the literature.

\section{Clinical utility}

Clinical management Utility

Confirmation of clinical diagnosis

Yes

Differential diagnosis Yes

Couple risk assessment Yes

Availability of clinical trials can be checked on-line at https://clinicaltrials.gov/

\section{References}

1. Spicer DE, Hsu HH, Co-Vu J, Anderson RH, Fricker FJ. Ventricular septal defect. Orphanet J Rare Dis 2014; 9:144.

2. Soto B, Becker AE, Moulaert AJ, Lie JT, Anderson RH. Classification of ventricular septal defects. Br Heart J 1980; 43:332-343.

3. Minette MS, Sahn DJ. Ventricular septal defects. Circulation 2016; 114(20): 2190-97. Erratum in: Circulation 2007; 115:e205.

4. Penny DJ, Vick GW 3rd. Ventricular septal defect. Lancet 2011; 377: 1103-12.

5. DakkakW, Bhimji SS. Ventricular Septal Defect. StatPearls (Internet) 2017, StatPearls Publishing, Treasure Island, Forida, United States. Available from http://www.ncbi.nlm.nih.gov/books/NBK470330/

6. Du ZD, Roguin N, Barak M, Bihari SG, Ben-Elisha M. High prevalence 
of muscular ventricular septal defect in preterm neonates. Am J Cardiol 1996; 78: 1183-85.

7. Corno A (2003). Atrioventricular septal defect. Congenital Heart Defects. Springer-Verlag Berlin Heidelberg 2003; 25-32.

8. Hoffman Jl. Congenital heart disease: incidence and inheritance. Pediatr Clin North Am 1990; 37(1): 25-43.

9. Janvier A, Okah F, Farlow B, Lantos JD. An infant with trisomy 18 and a ventricular septal defect. Pediatrics 2011; 127(4):754-59.

10. Hazan F, Aykut A, Unalp A, Mese T, Unal N, Onay H, Ozkinay F. Ventricular septal defect in Crouzon Syndrome: case report. Genet Couns 2012; 23(4):519-522.

11. Postma AV, van Engelen $K$, van de Meerakker J, Rahman T, Probst S, Baars MJ, Bauer U, Pickardt T, Sperling SR, Berger F, Moorman AF, Mulder BJ, Thierfelder L, Keavney B, Goodship J, Klaassen S. Mutations in the sarcomere gene MYH7 in Ebstein anomaly. Circ Cardiovasc Genet 2011; 4(1): 43-50.

12. Bettinelli AL, Mulder TJ, Funke BH, Lafferty KA, Longo SA, Niyazov DM. Familial ebstein anomaly, left ventricular hypertrabeculation, and ventricular septal defect associated with a MYH7 mutation. Am J Med Genet A 2013; 161 A(12):3187-90.

13. Wang J, Xie X, Zhou S, Huang G, Ma X, Suo P, Zhou S, Wang B, Ma $X$. The study of copy number variations in the regions of NOTCH1 among Chinese VSD and TOF patients. Int J Cardiol 2011; 147(3): 444-46.

14. Mohapatra B, Casey B, Li H, Ho-Dawson T, Smith L, Fernbach SD, Molinari L, Niesh SR, Jefferies JL, Craigen WJ, Towbin JA, Belmont JW, Ware SM. Identification and functional characterization of NODAL rare variants in heterotaxy and isolated cardiovascular malformations. Hum Mol Genet 2009; 18(5):861-71.

15. Czeizel A. Familial situs inversus and congenital heart defects. Am J Med Genet 1987; 28(1):227-28.

16. Deng X, Pan H, Wang J, Wang B, Cheng Z, Cheng L, Zhao L, Li H, Ma X. Functional Analysis of Two Novel Mutations in TWIST1 Protein Motifs Found in Ventricular Septal Defect Patients. Pediatr Cardiol 2015; 36(8):1602-09.

17. Zhu X, Deng X, Huang G, Wang J, Yang J, Chen S, Ma X, Wang B. A novel mutation of Hyaluronan synthase 2 gene in Chinese children with ventricular septal defect. PLoS One 2014; 9(2): e87437.

18. Wang J, Mao JH, Ding KK, Xu WJ, Liu XY, Qiu XB, Li RG, Qu XK, Xu YJ, Huang RT, Xue S, Yang YQ. A novel NKX2.6 mutation associated with congenital ventricular septal defect. Pediatr Cardiol 2015; 36(3): 646-656.

19. Zheng GF, Wei D, Zhao H, Zhou N, Yang YQ, Liu XY. A novel GATA6 mutation associated with congenital ventricular septal defect. Int J Mol Med 2012; 29:1065-1071.

20. Xuan C, Jia KG, Wang BB, Bai XY, Gao G, Yang Q, Wang XL, Liu XC, Ma X, He GW. Identification of two novel mutations of the HOMEZ gene in Chinese patients with isolated ventricular septal defect. Genet Test Mol Biomarkers 2013; 17(5): 390-94.

21. Cheng Z, Lib L, Li Z, Liu M, Yan J, et al. (2012) Two novel HAND1 mutations in Chinese patients with ventricular septal defect. Clin Chim Acta 413:675-677.

22. Wang B, Yan J, Mi R, Zhou S, Xie X, Wang J, Ma X. Forkhead box $\mathrm{H} 1$ (FOXH1) sequence variants in ventricular septal defect. Int J Cardiol 2010; 145(1): 83-85.

23. Pang S, Liu Y, Zhao Z, Huang W, Chen D, Yan B. Novel and functional sequence variants within the TBX2 gene promoter in ventricular septal defects. Biochimie 2013; 95(9):1807-1809.

24. Sun YM, Wang J, Qiu XB, Yuan F, Li RG, et al. (2016) A HAND2 Lossof-Function Mutation Causes Familial Ventricular Septal Defect and Pulmonary Stenosis. G3 (Bethesda) 2016; 6:987-92.

25. Yang SW, Hitz MP, Andelfinger G. Ventricular septal defect and restrictive cardiomyopathy in a paediatric TNNI3 mutation carrier. Cardiol Young 2010; 20(5):574-76.

26. Wang B, Li L, Xie X, Wang J, Yan J, Mu Y, Ma X. Genetic variation of SAL-Like 4 (SALL4) in ventricular septal defect. Int J Cardiol 2010; 145(2): 224-26.

27. Wang B, Yan J, Peng Z, Wang J, Liu S, et al. (2011). Teratocarcinoma-derived growth factor 1 (TDGF1) sequence variants in patients with congenital heart defect. Int J Cardiol 2011; 146(2): 225-27.

28. Xiao J, Kang G, Wang J, Li T, Chen J, Wang J, Li W, Wang B. A novel variation of GDF3 in Chinese Han children with a broad phenotypic spectrum of non-syndromic CHDs. Cardiol Young 2015; 25(7):1263-67.

29. Lee $\mathrm{CL}$, Hsieh KS, Chen YL, Shiue YL. Identification of candidate genes for congenital ventricular septal defects with HSA22q11 loss of heterozygosity. Rev Esp Cardiol 2009; 62:263-272.

30. Shen MM. Nodal signaling: developmental roles and regulation. Development 2007; 134(6): 1023-34.

31. Su D, Li Q, Guan L, Gao X, Zhang H, Dandan E, Zhang L, Ma X. Down-regulation of EBAF in the heart with ventricular septal defects and its regulation by histone acetyltransferase p300 and transcription factors smad2 and cited2. Biochim Biophys Acta 2013; 1832(12): 2145-2152.

32. Adam MP, Ardinger HH, Pagon RA, Wallace SE, Bean LJH, Stephens $K$, Amemiya A, editors. Seattle (WA): University of Washington, Seattle; GeneReviews 1993-2018; Available from: http://www.ncbi. nlm.nih.gov/pubmed/20301295.

33. Chen B, Gagnon M, Shahangian S, Anderson NL, Howerton DA, Boone JD; Centers for Disease Control and Prevention (CDC). Good Laboratory Practices for Molecular Genetic Testing for Heritable Diseases and Conditions. MMWR Recomm Rep. 2009; 58(RR6): 1-37; quiz CE-1-4. 